\title{
The predictors of physical activity among health volunteers based on pender's health promotion model
}

Mohammad Rahimian ${ }^{1}$, Maryam Mohammadi ${ }^{1,2}$, Ali Mehry ${ }^{1}$, Mohammad Hasan Rakhshani ${ }^{2}$

\author{
Journal of Research \& Health \\ Social Development \& Health Promotion \\ Research Center \\ Vol. 8, No. 4, Jul \& Aug 2018 \\ Pages: $305-312$ \\ DOI: $10.29252 / j r h .8 .4 .305$ \\ Original Article
}

1. Department of Health Education and Promotion, School of Health, Sabzevar University of Medical Sciences, Sabzevar, Iran 2. Correspondence to: Department of Public Health, School of Health, Shahid beheshti University of Medical Sciences, Tehran, Iran Email: M_Mohammadimm@yahoo.com

3. Department of Public Health, School of Health, Sabzevar University of Medical Sciences, Sabzevar, Iran

Received: 23 Jan 2016

Accepted: 12 Jun 2016

How to cite this article: Rahimian $\mathrm{M}$, Mohammadi M, Mehry A, Rakhshani MH. A survey on predictors of physical activity among health volunteers based on pender's health promotion model. J Research Health2018; 8(4): 305- 312

\begin{abstract}
One of the consequences of living in this century of machine and technology development is poverty in movement and reduction in physical activity. This study aimed to examine the predictive factors of physical activity in health volunteers based on the structures of Pender's health promotion model. This study was perform 80 health volunteers working at urban and rural health centers that were selected by multistage random sampling. Data were gathered by using a questionnaire for which the validity and reliability were confirmed. The results showed that despite a relatively high awareness about the benefits of physical activity (earning an mean score of $30.6 \pm 3.8$ on perceived benefits out of 40), 55\% of participants did not have a good physical activity. There was a significant positive correlation between physical activity behavior and health promotion model variables such as perceived barriers, perceived benefits, and self-efficacy. A total of $66.8 \%$ of the variance of physical activity behavior were explained by health promotion model variables that among them, self-efficacy, positive feelings associated with the behavior, and situational influences were the strongest predictor. According to the results, physical activity in health volunteers is low and interventions are needed to improve this behavior. The design of training programs for promotion of physical activity should be focused on strategies to strengthen self-motivation in individuals and families at their homes and improve workplaces.
\end{abstract}

Keywords: Health Promotion, Health Volunteers, Physical Activity

\section{Introduction}

One of the priorities of public health is sufficient physical activity [1]. Unfortunately, the life inthis century of machine and technology development has been accompanied by movement poverty and physical activity reduction in people [2]. Less activity or inactivity is a global public health problem and the main risk factor for high blood pressure, high blood glucose, abnormal blood lipids, overweight/obesity, and major chronic diseases such as vasculardiseases, cancer, and diabetes. The inactivity rate is high among communities regardless of being developed or developing $[1,3]$. According to the World Health Organization reports, lack of physical activity is the fourth major risk factor for mortality in the world [4]. The minimum 
physical activity needed to maintain and improve health in adults of moderate intensity is 30 minutes, 5 days a week [1]. Studies have shown that there isno regular physical activity in a large number of people [5]. The prevalence of inactivity in urban and rural areas calculated by focusing on leisure-time physical activity in age group 15-64 years among men, women, and both sexes were respectively $76.3 \%, 58.8 \%$, and $67.5 \%[3,4,6-8]$. The first step in training is to raise awareness about the significance of physical activity because awareness is probably leading to behavior change. Trained people who know how to constructively think will examine the situation for appropriate behavior flexibility $[9,10]$.

In order to plan for non-sanitary behavior change and health promotion, there are different theories and models. One of them is Pender's Health Promotion Model thatis rooted in socialcognitive, nursing, and public health theories. Pender's Health Promotion Model (HPM) uses a variety of individual characteristics and experiences, behavior-specific cognitions and affects to predict and explain health-promoting behavior [11]. Pender reports three concepts that are central to this model: individual characteristics and experiences, behavior specific cognitions and affect, and behavioral outcomes. Those studies utilizing the revised model indicate that perceived self-efficacy, benefits, and barriers are better predictors of a behavior and have greater influences on health related behaviors. While the HPM was developed to explain health promoting behaviors, it can also be used for healthprotecting behaviors. The HPM uses selected attitudes and beliefs such as perceived benefits and barriers, perceived self-efficacy, and interpersonal factors (such as norms, modeling, and support from others) to predict and explain health behavior [11] the structures of Pender's health promotion model are known as important determinants of physical activity behavior $[12,13]$. HPM is a descriptive model that predicts healthbehaviors. Meta-analysis reviews of the largenumber of studies adopting the model havedemonstrated its important contribution to the prediction of health behaviorslike physical activity and now its structuresare known as important determinants ofphysical activity behavior [14]. Most researchers use this model to study the behaviors that can lead to health promotion [14-16]. Previous studies have shown that perceived benefits, perceived barriers, perceived self-efficacy, and interpersonal influences have a significant impact on promotion of physical activity $[11,15,17,18]$. In general, the structures of health promotion model can predict behavior of physical activity $[8,19]$.

Health voluntary program is one of the successful community participations in social activities started in 1990 in Tehran, Iran, and the suburbs of other large cities such as Tabriz and Shiraz. It was expanded into all cities in 1993 and then into all villages in 1999. The health volunteers in Iran are usually housewives who have enough time and interest to engage in. They are asked to cover up and educate 50 families from their neighbors. They are known as unsalaried workers and a bridge between the community and health care system [20]. Training health volunteers who are in fact one of the members of the community seems effective in health promotion in the community. They are a successful experience of cooperation so that their participation in various studies has proven their honor [21]. As far as we know, there are no similar studies in Iran considering physical activity among health volunteers. Therefore, this study aimed to assess the physical activity of health volunteers by using Pender's Health Promotion Model.

\section{Method}

This cross-sectional research is a part of a three-month intervening study started in 2015 on 80 health volunteers in Torbat-eJam city, Khorasan Razavi province, Iran. The participants were selected according to the multistage random sampling method. According to the variant parameters and similar studies [8,11-13,22], the number of participants to be tested was estimated about 75 ; however, 80 participants were taken to ensure the results. 
The inclusion criteria of the research were: having at least one year work experience as health volunteer, being healthy enough to do physical activities, not being paralyzed, and signing the consent form to participate in the research.

Three kinds of questionnaires were designed and distributed for data collection as follows:

1) The Demographic Questionnaire that was used to gather personal information such asage, occupation, marital status, education level, body mass index, and place of residence.

2) The International Physical Activity Questionnaire (IPAQ) its Persian version approved in previous researches was used to evaluate the physical activity. It is a selfreporting questionnaire, which has been tested on adults of 18-65 in 20 countries and was approved. This questionnaire asks about the vigorous and moderate physical activities and walking practice during the last three weeks. We can extract and report the rate of physical activity based on a scoring protocol. The rate of physical activity in a week is estimated based on MET minutes/week (MET is a scale that is used to estimate the consumed energy during any physical activity. One MET equals to the amount of energy consumed by a relaxing person). In this protocol, all physical activities are classified as a multiple of energy consumption rate in the relaxing status. In this standard questionnaire, walking takes 3.3 METs, moderate physical activity takes 4 METs, and vigorous physical activity takes 8 METs. To calculate the total physical activity in a week, the amount of walking (3.3 MET $\times$ min $\times$ day) must be summed up with the amount of moderate physical activity $(4 \mathrm{MET} \times \min \times$ day), and vigorous physical activity $(8 \mathrm{MET} \times \min \times$ day $)$. For example, if one engaged in three types of physical activity during the last week including walking for 30 minutes a day for 4 days, moderate physical activity for 20 minutes a day for 3 days, and vigorous physical activity for at least 10 minutes a day for 1 day, the calculation is as follows:

$(4 \times 3.3 \times 30)+(3 \times 20 \times 4)+(1 \times 10 \times 8)=$ $716 \mathrm{METmin} /$ week.
Based on the obtained values, the participants were classified into three groups of inactive, minimally active, and active which are defined as follows:

Active person is one who has vigorous physical activity three days a week and has at least 1500 Metabolic Equivalent of Task (MET) $\mathrm{min} /$ week or goes walking at vigorous and moderate levels, or one who has 3000 MET -min/week in five days a week or more.

Minimally active person is one who has vigorous physical activity three days a week for at least 20 minutes each session; or goes vigorous and moderate walking five days a week or more, at least 30 minutes each session.

Inactive person does not have any physical activity or according to related physical activity reports, does not have criteria of vigorous or mode rate physical activity

3. A researcher made Questionnaire that was designed to measure the structures of the Pender's Health Promotion Model including: Perceived benefits (10 questions), perceived barriers (5questions), self-efficacy (8 questions), interpersonal influences (8 questions), positive emotion (5 questions), commitment (6 questions), modeling (8 questions), and competing preferences ( 7 questions). The validity of the questionnaire was confirmed by8 experts in the field and its reliability was calculated as 0.80 using Cronbach's alpha method. The perceived benefits, perceived barriers, and positive emotion were scored on the basis of 5-point Likert scale (from "very much" to "not at all").Self-efficacy, interpersonal influences, modeling, commitment, and competing preferences were scored on a 3-point scale (including "yes", "partly" or "no").

The instrument used in this study was a questionnaire designed by the researcher that was employed after confirming its content validity. For this purpose, the questionnaire of promotion-based health and scientific resources were provided and then were evaluated by 8 health education specialists with sufficient expertise and experience. They confirmed, applied, and validated the reformed version $(\mathrm{CVI}=0.98, \mathrm{CVR}=0.94)$. Test-retest reliability 
of the questionnaire was examined on 15 health volunteers within two weeks interval $(\mathrm{r}=0.90)$. The questionnaire consisted of two parts. The data from the questionnaire was then extracted and analyzed by SPSS 16 using independent T-test (to compare the scores of physical activity of the participants according to demographic parameters), Pearson's correlation coefficient (to determine the correlation between physical activity and Pender HPM parameters), and linear regression (to determine the predictors of health promotion model parameters).

\section{Results}

The participants had mean age of $25.1 \pm 2.5$ years with $4.1 \pm 2.8$ years experienced as health volunteer. $21.2 \%$ of them were educated below high school diploma, $62.6 \%$ had high school diploma, and $16.3 \%$ had an academic degree. $15 \%$ of participants were single and $85 \%$ were married. $88.8 \%$ of them were housewives, and mean Body Mass Index (BMI) was 25.01 \pm 4.1 . $40 \%$ of participants were living in urban and $60 \%$ in rural areas.

The results showed the mean score of perceived benefits was $31.3 \pm 4.5$ that indicates a good level of perceived benefits. However, selfefficacy score of $5.8 \pm 4.1$ and behavior score of $912.4 \pm 750.8$ were not satisfactory (Table 1).

The behavior of physical activity had a positive correlation with some variables of HPM such as perceived benefits, self-efficacy, and situational influences and a negative one with perceived barriers $(\mathrm{p}<0.01)$ (Table 2$)$.

Results showed that overall $66.8 \%$ of the variance of the physical activity behavior can be explained by health promotion model variables that among them, self-efficacy $(\beta \leq 0.230)$, positive emotions associated with the behavior $(\beta \leq 0.340)$ and situational influences $(\beta \leq 0.350)$ were the strongest predictors (Table 3 ).

The results of this study in relation to interpersonal influences showed that the mean score were as follows: social support from family $(0.7 \pm 0.3)$, from coach of volunteers $(0.7 \pm 0.3)$, from physician $(1.07 \pm 0.7)$, and from friends (1.03 \pm 0.6$)$;hence, the most support was from physician and friends.

The results showed that there was a statistically significant relationship between body mass index and physical activity. The mean score of physical activity in the volunteers with a low BMI value was higher than that of overweight and obese participants $(p=0.018)$. Also, a significant difference was observed between the mean physical activity scores and other demographic variables such as age, education level, place of residence, employment status, and marital status $(\mathrm{p}<0.05)$.

\begin{tabular}{lccc}
\multicolumn{4}{l}{$\begin{array}{l}\text { Table } 1 \text { Descriptive statistics } \\
\text { the scores of Pender's HPM }\end{array}$ and physical activity } \\
\hline $\begin{array}{l}\text { Description Scale } \\
\text { Structure }\end{array}$ & Mean & $\begin{array}{l}\text { Standard } \\
\text { deviation }\end{array}$ & Range \\
\hline $\begin{array}{l}\text { Physical Activity } \\
\text { (MET-minutes/week) }\end{array}$ & 912.4 & 750.8 & $318-3633$ \\
$\begin{array}{l}\text { Perceived benefits } \\
\text { Perceived barriers }\end{array}$ & 31.3 & 4.5 & $23-40$ \\
$\begin{array}{l}\text { Perceived self-efficacy } \\
\text { Interpersonal }\end{array}$ & 5.8 & 3.2 & $7-20$ \\
influences & 6.9 & 4.1 & $1-16$ \\
Modeling & 6 & 2.6 & $0-15$ \\
Commitment & 3.5 & 3.7 & $0-16$ \\
Competing preferences & 6.4 & 2.4 & $0-12$ \\
Positive emotion & 11.6 & 4 & $0-11$ \\
Situational influences & 3.1 & 3 & $3-20$ \\
\hline
\end{tabular}


Table 2 Correlation between physical activity and Pender's HPM parameters

\begin{tabular}{|c|c|c|c|c|c|c|c|c|}
\hline 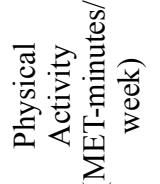 & 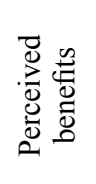 & 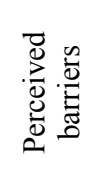 & 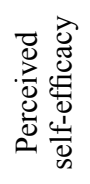 & 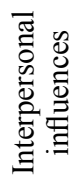 & $\frac{\infty}{: 0}$ & 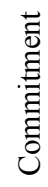 & 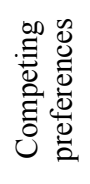 & 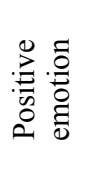 \\
\hline
\end{tabular}

\begin{tabular}{|c|c|c|c|c|c|c|c|c|c|}
\hline Perceived benefits & $.419 * *$ & & & & & & & & \\
\hline Perceived barriers & $-.423^{* *}$ & -.094 & & & & & & & \\
\hline $\begin{array}{l}\text { Perceived } \\
\text { self-efficacy }\end{array}$ & $.543^{* *}$ & $.361 * *$ & $-.476^{* *}$ & & & & & & \\
\hline $\begin{array}{l}\text { Interpersonal } \\
\text { influences }\end{array}$ & .197 & -.075 & -.121 & .110 & & & & & \\
\hline Modeling & .002 & -.176 & .026 & -.170 & $.736^{* *}$ & & & & \\
\hline Commitment & $.364 * *$ & $.492 * *$ & -.091 & $.302 * *$ & $.299 * *$ & .042 & & & \\
\hline $\begin{array}{l}\text { Competing } \\
\text { preferences }\end{array}$ & -.155 & -.152 & -.218 & $.252 *$ & .178 & -.035 & .207 & & \\
\hline Positive emotion & $.556^{* *}$ & $.240^{*}$ & $-.334 * *$ & $.316^{* *}$ & .122 & .160 & .067 & $-.237^{*}$ & \\
\hline $\begin{array}{l}\text { Situational } \\
\text { influences }\end{array}$ & $.480 * *$ & $.277^{*}$ & -.007 & .211 & $.399 * *$ & .201 & $.519^{* *}$ & -.052 & .045 \\
\hline
\end{tabular}

Table 3 Regression analysis of physical activity behavior based on HPM variables

\begin{tabular}{|c|c|c|c|c|c|}
\hline Independent Variables & B & $\beta$ & $\mathrm{p}$-value & R Square & Dependent Variable \\
\hline Perceived benefits & 10.1 & .61 & .511 & \multirow{9}{*}{.668} & \multirow{9}{*}{$\begin{array}{c}\text { Physical activity } \\
\text { Behavior }\end{array}$} \\
\hline Perceived barriers & -48.3 & -.208 & .014 & & \\
\hline Perceived self-efficacy & 42.3 & .234 & .016 & & \\
\hline Interpersonal influences & 25 & .89 & .474 & & \\
\hline Modeling & -28 & -.142 & .225 & & \\
\hline Commitment & 17.2 & .56 & .567 & & \\
\hline Competing preferences & -48 & -.182 & .038 & & \\
\hline Positive emotion & 64.5 & .347 & .001 & & \\
\hline Situational influences & 85.5 & .351 & .001 & & \\
\hline
\end{tabular}

\section{Discussion}

The mean score of physical activity in this study was 912.4 that indicated a poor level of physical activity. This finding is consistent with the result of a study conducted in urban areas of Yazd (prevalence rate of 54.4\%), and with that of another research by Irwin [23] that showed that more than one-half of university students in the United States and Canada were not active enough to gain health benefits. Emami and colleagues [1] also examined physical activity in health volunteers in Tehran and estimated the participants' inactivity rate as $36.3 \%$. Lack of physical activity in the population of the city of Tehran may be resulted from better access to sports facilities and support from the organizations.

Research results of Aghamolaie et al [24] that examined efficacy, perceived benefits, and barriers to physical activity in the students of Hormozgan showed that $73.5 \%$ of the subjects 
did not have appropriate physical activity. The study conducted by Jalilian et al. [25] at the Hamadan University of Medical Sciences showed that 65 percent of employed women do not have enough physical activity which is less desirable than the current survey results. This may be due to the better awareness of benefits of physical activity among health volunteers or due to the differences in measurement instruments. While in the studies of most countries such as America, and Lebanon, the numbers of physically active persons are high, the National Centre for Chronic Diseases Prevention in America reported that more than half of adults in that country do not have enough physical activity [26]. The findings of this study indicated that there is a significant relationship between the amount and intensity of physical activity in volunteers with body mass index so that physical activity in people with normal BMI was higher than that of overweight and obese people. This result is in agreement with those obtained by Mohammedian and colleagues [27] who investigated the relationship between physical activity and body mass index among students in Semnan and the findings of Norouzi and colleagues [28]. Obesity may result in physical inactivity, poor diet, and poor lifestyle while being physically active seems to play a crucial role in burning extra calories and create proper eating habits and way of life.

The results of the study showed that the highest social support was from physician and friends while the coach of volunteers did not have this kind of behavior. Also, family members did not provide desirable support for volunteers. The study conducted by Teymuri [12] examining health promotion model among students of Sanandaj, presented family members, relatives, and friends as the sources of perceived social support. Therefore, intervention programs are recommended to promote physical activity by a focus on the role of volunteers, doctors, coaches, friends, and family members.

In the present study, an mean score of 5.7 out of 16 was achieved on self-efficacy which represents a low self-efficacy toward physical activity. Similar findings have been reported by
Karimi et al [11] and Mazloomy and colleagues [29]. Since self-judgment and ability are defined to organize and execute an activity, it can be concluded that volunteers do not believe in their ability to perform physical activities.

In this study, factors including lack of sports facilities, lack of time, and high cost, in sequence, were understood as the most important barriers to the access to sports facilities. Karimi et al [11] introduced being busy and Aghamolaei et al. [24] suggested lack of time as major obstacles to engaging in physical activity and sport.

Obtaining an mean score of 31 out of 40 in this study shows that participants were aware of benefits of physical activity which is consistent with the results of Aghamolaei [24] and Karimi [11].

Significant positive correlation between physicalactivity behavior and perceived benefits and perceived self-efficacy indicated that when volunteers gain a better understanding of the benefits of a behavior and self-confidence, they will perform that behavior.

The positive significant relationship between physical activity and commitment to action and positive emotion toward behavior was proven in this survey. This finding shows that more commitment of volunteers to their behavior and more positive feeling can promote physical activity behavior.

A strong positive correlation between physical activity and situational influences indicates if sports facilities are provided for the volunteers, they will exhibit more physical activities.

A negative significant correlation between physical activity and perceived barriers to physical activity in this study suggests the significant role of physical barriers to healthy behaviors.

Based on the results from the structures of health promotion, self-efficacy, perceived barriers, positive emotion toward the behavior, and situational influences were the most important predictors of physical activity behavior, which is consistent with the findings of similar studies [11,30-32]. In this study, a total of $66.8 \%$ of the variance of 
physical activity behavior were explained by the variables of health promotion model. On the basis of these results, this model can be used to estimate the amount of physical activity in health volunteers to improve the plan of action. the study sample was drawn only from community health service in the regions of torbat-e jam. in the areas may have different results. in addition, self-report is less reliable for identifying individual with physical activity performance, which in the future studies could be a combination of self-report, interview or direct observation of behavior of skills.

\section{Conclusion}

According to the results obtained from this study, using development models, especially health promotion model, seems necessary to enhance self-efficacy and reduce perceived barriers to a behavior. It is also recommended to provide physical facilities and proper environment alongside effective interventions in order to create incentives for mobility in education and training programs for individuals.

\section{Acknowledgments}

This study is extracted from an academic research thesis with ethical cod "IR.MEDSAB. REC.1394.61" supported by Sabzevar university of medical sciences which was conducted in the city of Torbat-e- Jam. The authors would like to acknowledge respected authorities of Torbat-ejam city health center and health volunteers who participated in this study.

\section{Contribution}

Study design: MM, MR, AM

Data collection: MR

Data analysis: MHR, MR

Manuscript preparation: AM, MM, MR

\section{Conflict of Interest}

"The authors declare that they have no competinginterests in this manuscript"

\section{Funding}

The author (s) received no financial support for the research, authorship and/or publication of this article.

\section{References}

1- Emami RS, Eftekhar-Ardebili H, Golestan B. Effect of a health education intervention on physical activity knowledge, attitude and behavior in health volunteers. Journal of Nursing and Midwifery Sciences2011; 16(4): 48-55.

2- Moeini B, Rahimi M, Hazaveie SMM, Allahverdipoor H, Moghimbeygi A, Mohammadfam I. Effect of education based on trans-theoretical model on promoting physical activity and increasing physical work capacity. Journal of Military Medicine2010; 12(3): 123-30.

3- Moattari M, Shafakhah M, Sabet-Sarvestani R. Assessing stages of exercise behavior change, self efficacy and decisional balance in Iranian nursing and midwifery students. International Journal of Community Based Nursing and Midwifery2013; 1(2): 121-9.

4- Ramezankhani A, Tavassoli E, Motalebi-Ghayen M, Gharli-pour Z. The study of knowledge, attitude and practice towards physical activity college students living on campus in Shahid Beheshti University of Medical Science. Journal of Health Education and Health Promotion2013; 1(1): 13-20.

5- Alwan A. Framework for health information systems and core indicators for monitoring health situation and health system performance: estern mediterranea region report 2014. Available at URL: http://applications.emro. who.int/dsaf/EMROPUB_2014_EN_1792.pdf?ua=1. Accessed Oct 4, 2014.

6- Saber F, Shahnazi H, Sharifrad G. The survey of theory of planned behavior constructs regarding girl student's physical activity in Naein Payame Noor university. Journal of Health System Research2013; 9(9): 1041-21.

7- Solhi M, Zinat-Motlagh F, Karimzade-Shirazi K, Taghdisi MH, Jalilian F. Designing and implementing educational program to promote physical activity among students: an application of the theory of planned behavior. Horizon of Medical Sciences2011; 18(1): 53-4.

8- Taymoori P, Niknami SA, Ghofranipour F, Berry T, Kazemnejad A. Application of the health promotion model to predict stages of exercise behaviour in Iranian adolescents. East Mediterr Health J2009;15(5):1215-25. 9- Jouhari Z, Pirasteh A, Davati A, Mohamadi J. The effect of educational intervention in volunteer's earthquake knowledge in health centers of eastern Tehran. Journal of Shahed University2013; 20(103): 1-10.

10- Shakeri M, Fekri S, Shahnavaz A. The effect of educational program based on basnef model on the pregnant mothers' physical activity. Journal of Urmia Nursing And Midwifery Faculty2013; 10(6): 832-40.

11- Karimi M, Eshrati B. The effect of health promotion model-based training on promoting students' physical 
activity. Journal of Kermansha University of Medical Sciences2012; 16(3): 192-200.

12- Taymoori P, Falhahi A, Esmailnasab N. Application of the health promotion model in studying physical activity behavior of students in Sanandaj, Iran. Scientific Journal of School of Public Health and Institute of Public Health Research2011; 9(1): 35-46.

13- Taymoori P, Niknami SA, Ghofranipour F. Effects of a school-based intervention on the basis of pender's health promotion model to improve physical activity among high school girls. Armaghane Danesh Journal2007: 12(2): 47-59.

14- Radmehr M, Ashktorab T, Neysi L. Effect of the educational program based on Pender's theory on the health promotion in patients with obsessive- compulsive disorder. Journal of Nursing Education2012; 2(3): 56-63.

15- Guedes NG, Moreira RP, Cavalcante TF, De Araujo TL, Ximenes LB. Students' physical activity: an analysis according to Pender's health promotion model. Rev Esc Enferm USP2009; 43(4): 774-80.

16- Heydari A, Khorashadizadeh F. Pender's health promotion model in medical research. J Pak Med Assoc 2014; 64(9): 1067-74.

17- Teerarungsikul N, Phuphaibul R, Loveland-Cherry CJ, Pookboonmee R, Kijboonchoo K, Nityasuddhi D. Effectiveness of a physical activity promotion program on perceived self-efficacy, physical activity and physical fitness among thai adolescent girls. Thai J Nurs Res2009; 13(2): 81-94.

18- Charkazi A, Fazli L, Alizadehi F, Fazelnia A, Kouchaki GM, Bakhsha F. Evaluation of regular physical activity and its association with psychological constructs based on transtheoretical model among student of Golestan university of medical sciences. Iranian Journal Health Education \& Promotion Association2014; 1(4): 57-68.

19- Vahedian-Shahroodi M, Amin-Shokravi F, Haidarnia A, Jabbari-Nooghabi H. A survey on the effects of the pender's health promotion model on prediction of the employees' physical activity. Health Educ Health Promot2013; 1(1): 51-66.

20-Taghdisi MH, Abolkheirian S, Hosseini F. Effectiveness of education and its influential factors on empowerment of the health volunteers in the west of Tehran health center. Iranian Journal of Occupation Health2011; 8(2): 1-7.

21- Bayati A, Mohammadbeigi A, Eshrati B, Jafari M. Effect of first aid educational program in health volunteers, rescue method during disasters in Arak. Arak Medical University Journal2009; 12(2): 1-7.

22-Taymoori P, Luban D, Berry TR. Evaluation of the health promotion model to predict physical activity in Iranian adolescent boys. Health Educ Behav2010;37(1):84-96.

23- Irwin JD. Prevalence of university students' sufficient physical activity: a systematic review. Percept Mot Skills2004; 98(3 Pt 1): 927-43.

24- Agha-Mollaii T, Tavafian SS, Hasani L. Selfefficacy, perceived benefits and barriers to regular physical activity at the university of medical sciences. Iranian Journal of Epidemiology2003; 3(2): 9-15.

25- Jalilian F, Emdadi SH, Mirzaie M, Barati M. The survey physical activity status of employed women in Hamadan university of medical sciences: the relationship between the benefits, barriers, self-efficacy and stages of change. The Journal of Toloo-e-Behdasht2011; 9(4): 89-99.

26- Sallis JF, Haskell WL, Wood PD, et al. Physical activity assessment methodology in the five-city project. Am J Epidemiol1985; 12(1): 91-106.

27- Doost Mohammadian A, Keshavarz SA, Dorosti AR, Mahmudi M, Sadr Zadeh H. The nutritional status and the relationship between physical activity and nutrition attitude with a body mass index for age in high school girls (18-14) years old. Koomesh Journal2004; 6(3): 178-94.

28- Noroozi A, Ghofranipour AR, Tahmasebi R, Heidarnia AR. Determinants of physical activity based on Health Promotion Model (HPM) in diabetic women of Karaj diabetic institute. Iranian South Medical Journal2010; 13(1); 41-51.

29- Mazloomy Mahmoudabad SS, Mohammadi M, Morovati Sharifabad MA. Exercise and Its relation to self efficacy based on stages of change model in employees of Yazd in 2008. Journal of Kerman University of Medical Sciences2010; 17(4): 346- 54.

30- Chenary R, Noroozi A, Tahmasebi R. Survey of effective factors on health promotion behaviors based on health promotion model in chemically injured veterans of Ilam Province in 2012-13. Scientific Journal of Ilam University of Medical Sciences2013; 21(6): 257-67.

31- Rahimi T, Dehdari T, Ariaeian N, Gohari MR. Survey of breakfast consumption status and its predictors among Qom students based on the Pender's health promotion model constructs. Iranian Journal of Nutrition Sciences \& Food Technology2012; 7(2); 75-84.

32- Mehri A, Morowati Sharifabad M. Utilizing the health promotion model to predict oral health behavior in the student of Islamic Azad university of Sabzevar. Journal of Dentistry of Tehran University of Medical Sciences 2009; 22(1): 81-7.

\footnotetext{
Copyright (C) 2016 ASP Ins. This open-access article is published under the terms of the Creative Commons Attribution-NonCommercial 4.0 International License which permits Share (copy and redistribute the material in any medium or format) and Adapt (remix, transform, and build upon the material) under the Attribution-NonCommercial terms.
} 